\title{
An Unusual Complication of Oral Hygiene - Traumatic Implantation of a Toothbrush
}

\author{
Rubik Ray ${ }^{1}$, Debasish Mondal², Avijeet Mukherjee ${ }^{3}$
}

${ }^{1}$ Department of General Surgery, All India Institute of Medical Sciences, Raipur, Chhattisgarh, India. 2, 3 Department of General Surgery, College of Medicine and JNM Hospital, Kalyani, West Bengal, India.

\section{INTRODUCTION}

Brushing of teeth is an activity practised daily and is important for the maintenance of oral hygiene. Serious injury by a toothbrush is a very rare event. However sometimes it can be a cause of severe oropharyngeal trauma. Here we report this unusual complication of maintaining oral hygiene where a five year old girl suffered from traumatic implantation of a toothbrush in her oral cavity due to an accidental fall. Although not very common, this daily activity of maintaining oral hygiene can result in very serious oropharyngeal injuries. The risks of undergoing any operation under general anaesthesia cannot be overlooked either. The authors suggest that using silicone finger toothbrush instead of regular ones in children might be a safer alternative.

\section{PRESENTATION OF CASE}

A five-year-old girl presented to the emergency with oral trauma by toothbrush. On history the parents explained that the girl was walking while brushing her teeth when she tripped on the door sill and fell face forward onto the floor. On examination the patient was found to be in pain and unable to talk. There was an adult sized toothbrush impacted in the left cheek through the left lower vestibule (Figure 1). CT of face showed the entire front portion of the toothbrush containing the bristles was deep into the buccal mucosa impinging onto the muscle (Figure 2). The patient, after proper preoperative preparation, was taken to the operating room and the toothbrush was taken out under sedation general anaesthesia.

During operation the mucosal wound was slightly enlarged for proper delivery of the bristles without causing additional trauma. Wound was repaired by absorbable sutures. Post-operative recover was uneventful.

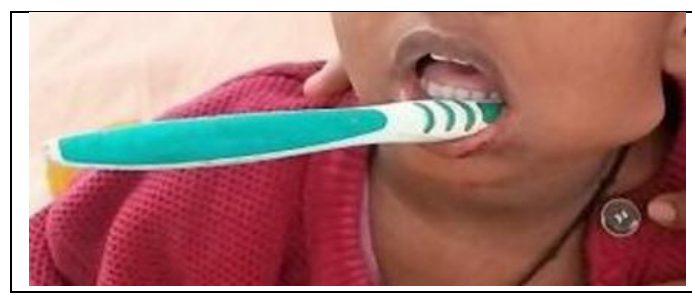

Figure 1. Adult-Sized Toothbrush Implanted in Left Cheek
Corresponding Author:

Dr. Rubik Ray,

Department of General Surgery,

AIIMS Raipur,

Raipur - 492099,

Chhattisgarh, India.

E-mail: rubikray@gmail.com

DOI: $10.14260 /$ jemds/2021/54

How to Cite This Article:

Ray R, Mondal D, Mukherjee A. An unusual complication of oral hygiene-traumatic implantation of a toothbrush. $J$ Evolution Med Dent Sci 2021;10(04):246-247, DOI: 10.14260/jemds/2021/54

Submission 01-08-2020,

Peer Review 26-11-2020,

Acceptance 03-12-2020,

Published 25-01-2021.

Copyright (c) 2021 Rubik Ray et al. This is an open access article distributed under Creative Commons Attribution License [Attribution 4.0 International (CC BY 4.0)] 


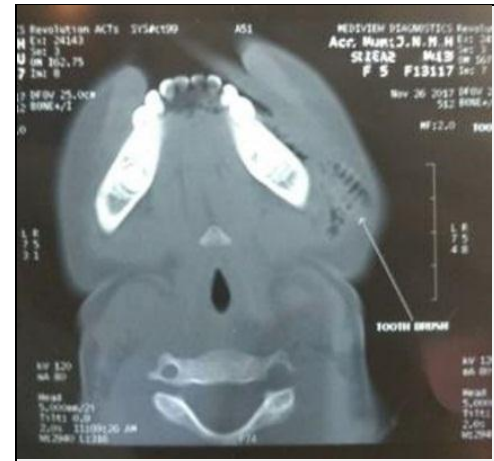

\section{Figure 2.}

CT Scan Showing Bristles of Toothbrush Impacted in Soft Tissue of Left Cheek

\section{DISCUSSION}

Brushing of teeth is an innocuous activity practised by everyone daily. However sometimes this harmless activity can be a cause of serious oropharyngeal trauma, especially in children requiring even general anaesthesia and surgery. In fact incidents of traumatic implantation of toothbrush have been reported occasionally. ${ }^{1,2}$ These happen mostly in children or patients with epilepsy. ${ }^{3}$ These incidents illustrate that introduction of a foreign object, that too a rigid and pointed one, inside a body cavity is hazardous activity, however, innocuous it might appear, particularly when done on a daily basis. The risks of undergoing a totally avoidable surgical procedure under general anaesthesia cannot be overlooked either. Instillation of proper disciple in children, as well as parental supervision is advocated to avoid such serious complications of such an apparent harmless daily activity.

Financial or other competing interests: None.

Disclosure forms provided by the authors are available with the full text of this article at jemds.com.

First author was responsible for research and preparation of manuscript whereas second and third authors were the primary surgeons dealing with patient management.

\section{REFERENCES}

[1] Moran AJ. An unusual case of trauma: a toothbrush embedded in the buccal mucosa. $\mathrm{Br}$ Dent J 1998;185(3):112-4.

[2] MacLeod SP. Traumatic implantation of a toothbrush: an unusual hazard of oral hygiene. ASDC J Dent Child 1989;56(1):69-70.

[3] Kumar S, Gupta R, Arora R, et al. Severe oropharyngeal trauma caused by toothbrush-case report and review of 13 cases. Br Dent J 2008;205(8):443-7. 